\title{
Evaluation of the Coefficient of Friction for Crystalline Fe Grains Long Segregant-Atoms Layers on the Grain Boundaries in Reciprocal Sliding
}

\author{
Sergey Bulgarevich ${ }^{1}$, Michael Boiko ${ }^{1} \&$ Andrew Sidashov ${ }^{1}$ \\ ${ }^{1}$ Rostov State Transport University, 2 Narodnogo opolchenia Square, Rostov-on-Don, Russia \\ Correspondence: Sergey Bulgarevich, Rostov State Transport University, 2 Narodnogo Opolchenia Square, \\ Rostov-on-Don 344038, Russia. Tel: 7-863-255-3445. E-mail: bulgarevich@rambler.ru
}

Received: March 16, 2013 Accepted: June 3, 2013 Online Published: August 21, 2013

doi:10.5539/jmsr.v2n4p45 URL: http://dx.doi.org/10.5539/jmsr.v2n4p45

\begin{abstract}
Properties of polycrystalline metal alloys such as endurance and solidity as well as their conservation under high and low temperatures, are determined by the chemical composition, polycrystalline structure of the alloy and mostly by the grain boundaries peculiarities. Adsorptive film-type layers of alloying and extrinsic components, which develop on the grain boundaries as a result of a surface segregation and diffusion, treated as a third component or a body, which acts as lubricant between two interacting grains, thus making grain sliding and material destruction processes easier. During our research we have evaluated the friction coefficient between polycrystalline iron grains, which have different tentative segregant layers on their surfaces. We have also revealed the friction coefficient's periodic dependence on the segregant's atomic number. Was determined out that the higher the friction coefficient is, the tighter the link between the polycrystalline materials can be observed.
\end{abstract}

Keywords: segregant-atoms, polycrystalline material, grain boundaries, grain surface, friction coefficient, coefficient of sliding friction, segregation and diffusion processes

\section{Introduction}

Materials contact fatigue is one of the most common defects, which is especially peculiar to the railway transport and rail wheels. Composition of the thin layer on the wheel's rolling surface is inevitably influenced both by cyclic and thermal loads. The wheel's interaction with other components of a single tribological system, which is made up of three basic elements, mainly, a wheel itself, a rail and a brake block, is not the least of the influence factors. Exchange-diffusion processes, which occur between a brake block's polymer composition and the wheel's rolling surface, made it possible to determine the chemical elements' transition from the brake block composition into the wheel.

Strength properties of the wheel and rail steels are determined by their polycrystalline structure, as well as by the chemical composition of the grain boundaries (Kolesnikov et al., 2006). Weakening of both strength and wear-resistant properties of polycrystalline materials, compared to the monocrystalline ones, is due to their having intercrystalline boundaries, which possess lower strength properties, than those of the grains. Previous works (Kolesnikov et al., 2006; Seah, 1980) studied the influence of the grains boundaries' chemical composition on the surface defects, occurring on the wheel's rolling surface, however, specific wheel steel grades were considered. It was found out (Kolesnikov et al., 2006; Seah, 1980) that the composition of the thin layer (a few tens of angstrom) on the wheel rolling surface depends not only on the steel basic composition, but also on the alloying and impurity components, penetrating the grain boundaries, and thus generating the defects formation on the wheel's rolling surface.

\section{Methods}

Let us analyze the process of the segregants' layers gradual accumulation.

1). If it is assumed that the process of the segregants' diffusion from crystal grains into the grain boundary surface is based on the vacancy mechanism, in this case it is necessary for an atom to be placed near a vacancy to 
make a diffusion skip (transition) within the material. The equilibrium concentration of vacancies $n$ in crystalline material according to Boltzmann distribution (Heinecke, 1984) may be written:

$$
n=N_{A} e^{-\frac{E_{v a c}}{\mathrm{k} T}},
$$

where $N_{A}$ is Avogadro's number, $\mathrm{k}$ is Boltzmann constant, $E_{\text {vac }}$ is vacancy formation energy. $E_{\text {vac }}=9 \mathrm{k} T_{\text {mel }}$, where $T_{m e l}$ is the melting point of the material, inside which vacancies are formed (Heinecke, 1984), and also it suggests the temperature, at which the saturated concentration of vacancies is reached (Kozakov et al., 2007).

According to the carbon steels' state diagram $T_{m e l}$ ranges from 1418 to $1673 \mathrm{~K}$ (Sorokin et al., 1989). At $300 \mathrm{~K}$ temperature the volume $x$ is from $4.5 \cdot 10^{-19}$ to $2.2 \cdot 10^{-22}$ mole fractions, and at $900 \mathrm{~K}$-it will vary from $7.6 \cdot 10^{-7}$ to $6.0 \cdot 10^{-8}$ mole fractions. The content of sulfur $(\mathrm{S})$ and phosphorus $(\mathrm{P})$, the most dangerous segregants, as impurities in wheel and type steels does not exceed the amount of $0.04 \%$ in mass (Sorokin et al., 1989). In the base material it will correspond to $4.0 \cdot 10^{-4}$ of mole fractions approximately. Comparison of this number to the vacancies' concentration amount shows that at room temperature their content is by 15-18 orders less than that of impurities, while at $900 \mathrm{~K}$ temperature it is by 3-4 orders less. Thus, it is obvious, that the mechanism of the segregants' diffusion from crystalline grains can't be the vacancy one.

2). If it is proposed that the diffusion process is based on the dislocation mechanism, then it should at first be noted, that the dislocations, especially the edge ones, play a significant role in the segregation process. The probability of the segregant's atom emergence on the grain surface is much higher at the atom-dislocation interaction than in case of dislocation diffusion. Edge dislocations, having points of contact with the grain surface, generate the impurity and alloying elements transition from the grain core to the grain boundary surface.

If supposing, that edge dislocations are the catalysts, which stimulate the segregation reaction, according to the well known scheme of homogeneous catalysis (Panchenkov \& Lebedev, 1974), then it gives:

$$
\begin{gathered}
S+d i s l_{\leftarrow} \text { Sdisl (fast), } \\
\text { Sdisl }+M \rightarrow S M+\text { disl (slowly), }
\end{gathered}
$$

where $S$ is the segregant inside the solid grain, disl is the dislocation inside of the grain, Sdisl is the intermediate (the segregant and dislocation compound), $M$ is a particle of the grain boundary, $S M$ is the segregant on the grain boundary surface. The segregant, trapped inside the dislocation, will continue diffusing in the dislocation tube till its eventual leaving it and emerging on the grain boundary surface, afterwards fixing on it. This non-equilibrium process is flowing much slower (reaction 3), than the equilibrium is reached (2).

The values of the processes rates (2), (3) may be determined, considering the mass action law. For the balanced reaction (2) the direct and reverse reactions are equal (2), thus:

$$
k_{1}[S]\left\{[\text { disl }]^{0}-[\text { Sdisl }]\right\}=k_{2}[\text { Sdisl }],
$$

where $k_{1}$ and $k_{2}$ are the rate constants of both direct and reverse reactions (2), $[S]$ is the current concentration of segregants in the grain solid media, $[\mathrm{dis} l]^{0}$ is the initial concentration of dislocations in the material's grain, $[\mathrm{S} d i s l]$ is the current concentration of the segregant and the dislocation compound, thus:

$$
k_{1}[S][\text { disl }]^{0}=k_{2}[S d i s l]+k_{1}[S][S d i s l],
$$

Segregation reaction (3) rate $V_{\text {segr }}$ is proportional both to the product of the current concentration of the segregant and the dislocation compound, and to the concentration of the vacant grain boundary surface $[M]$ :

$$
V_{\text {segr }}=k_{3}[\operatorname{Sdisl}][M] .
$$

Hence

$$
V_{\text {segr }}=\frac{k_{1} k_{3}[S][M][\text { disl }]^{0}}{k_{1}[S]+k_{2}} .
$$

From the Equation (7) it is clear that the rate of the segregation process is proportional to the initial dislocations' concentration inside the solid (the grain), as well as to the concentration of vacant wall particles, not occupied by 
the segregants' atoms (free grain boundary surface). If a dislocation can "catch" the segregant's atom immediately $\left(k_{1}[S]>>k_{2}\right)$, then the segregation rate may be only directly proportional to the initial dislocations' concentration and to the volume of free segregation surface:

$$
V=k_{3}[M][\text { disl }]^{0}
$$

If it is assumed that the segregation process at wheel steel operation is a mechanically activated one, and then $[\mathrm{dis} l]^{0}$ is proportional to the mechanical energy, that is applied to the pattern per unit of time (dislocations formation and decaying process). In the work (Bulgarevich et al., 2006), where the methods of non-equilibrium thermodynamics have been applied, it is shown that in the friction contact zone the friction process can activate any chemical reactions, which will have negative chemical affinity, as well as cause the dislocations occurrence on the near-surface layers of the material. If the mechanical activation process is considered as stationary, in this case $[\mathrm{disl}]^{0}$ is a constant value, and the Equation (8) can be rearranged into Equation (9):

$$
V_{\text {segr }}=k^{\prime}[M],
$$

where $k^{\prime}=[\mathrm{dis} l]^{0}$ is rate constant of the segregation process. The expression (9) corresponds to the kinetic differential equation of the first order segregation:

$$
-\frac{d M}{d \tau}=k^{\prime}[M] .
$$

Dividing and integrating the variables (10) gives:

$$
\ln [M]=-k^{\prime} \tau+\text { const }
$$

At the initial conditions $\tau=0$, const $=\ln [M]^{0}$, where $[M]^{0}$ is the initial concentration of the vacant particles on the grain boundary, then it can be expressed:

$$
\frac{[M]}{[M]^{0}}=e^{-k^{\prime} \tau}
$$

If it is assumed that $x$ is the portion of the metal grain boundary surface, taken by the segregants, and then $\frac{[M]}{[M]^{0}}=1-x$ is the portion of the grain vacant boundary surface.

The reaction constant rate can be estimated both from the Equations (9) and (12) and from the published data of model experiments with austenitic steels. The latter have determined various segregants' content on the grain boundaries in the course of time. In the work (Ermakova, 2006), where the Auger spectroscopy was applied, S content on the grain boundaries, determined in atomic per cent, under different time influence and at temperatures 1173 and $1273 \mathrm{~K}$ respectively was presented in curves in Figure 1. 


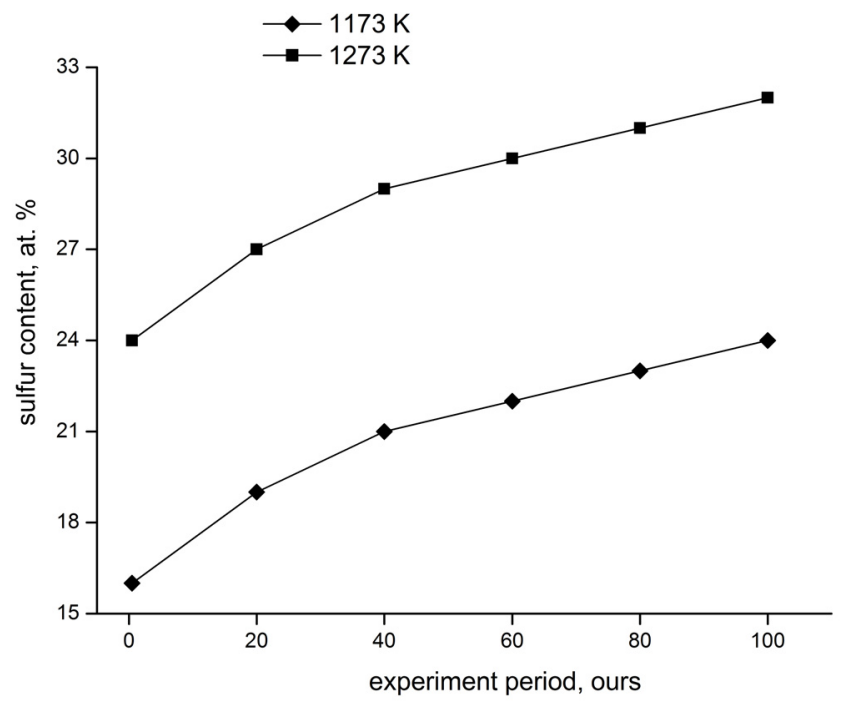

Figure 1. The time and temperature influence on the grain boundary segregation in austenitic Fe-C alloy steel

Following the curves the volume $\frac{[M]}{[M]^{0}}=1-x$ was calculated, it corresponds to $(100 \%-\mathrm{C} \% \mathrm{~S}) / 100 \%$ from the ordinate point in Figure 1. From the formula (12) rate constant volumes $k_{l}{ }^{\prime}=0.0009 \mathrm{~h}^{-1}$ for temperature $1173 \mathrm{~K}$ and $k_{2}{ }^{\prime}=0.001 \mathrm{~h}^{-1}$ for temperature $1273 \mathrm{~K}$ were distinguished. These data make it possible to estimate the activation energy of the segregant's rising on the grain surface according to the reaction (3), based on formula to calculate the activation energy $E_{a}$ of chemical reaction at two given temperatures, thus (Panchenkov \& Lebedev, 1974):

$$
\ln \frac{k_{1}{ }^{\prime}}{k_{2}{ }^{\prime}}=-\frac{E_{a}}{k}\left(\frac{1}{T_{1}}-\frac{1}{T_{2}}\right) .
$$

Where $k_{1}$ ' and $k_{2}$ ' are reaction rate constants of segregation at $T_{1}$ and $T_{2}$ respectively. Application of the above volumes of $k_{1}{ }^{\prime}$ and $k_{2}{ }^{\prime}$ as well as the temperatures $T_{1}=1273 \mathrm{~K}$ and $T_{2}=1173 \mathrm{~K}$ gives $E_{a}=2.17 \cdot 10^{-20} \mathrm{Dg}$. Comparison of the obtained volume to the activation energy of vacancy diffusion inside the solid might be interesting to analyze. Thus, according to (Heinecke, 1984) the latter is equal to $E_{a}{ }^{V}=8 \mathrm{k} T_{m e l}$. Considering the fact, that $T_{m e l}$ can range from 1418 to $1673 \mathrm{~K}$, corresponds to the data of the carbon steel state diagram (Sorokin et al., 1989), we have $E_{a}{ }^{V}=\left(1.56 \cdot 10^{-20}\right) /\left(1.85 \cdot 10^{-19}\right) \mathrm{Dg}$. Thus, the activation energy of vacancy diffusion inside the grain exceeds $\mathrm{S}$ activation energy of segregation at 7.2-8.5 times approximately. The result is significant enough and greatly supports the assumption of the substitutional mechanism of the segregation. It is clear that the process of the segregant's leaving the dislocation tube is more advantageous, since it does not take much energy, nor it needs the matrix atoms unlike in case of the vacancy diffusion process. The mole activation energy of segregation is defined as $\mathrm{Ea}=1573 \cdot \mathrm{k} \cdot N_{A}=13 \mathrm{kDg} / \mathrm{mole}$ and by its order is equal to the physical adsorption. The time of the polycrystalline safe operation can be defined as $\tau_{l}$; on the certain time period the free grain boundary part between the grains is going to reduce up to $e$ times from the initial segregant's emergence on the surface, thus $\frac{[M]}{[M]^{0}}=\frac{1}{e}$. The above estimations considered the segregant's properties of sulfur and were based on the data of work (Bulgarevich et al., 2006). From the Equation (12) the volume $\tau_{l}=\frac{1}{k^{\prime}}$, at $600 \mathrm{~K}, \tau_{l}=0.5$ years, at $300 \mathrm{~K}, \tau_{l}=6.1$ year. It should be noted, that in this the study the segregation was analyzed as a thermally activated process only.

In fact, damaging the wheel's rolling surface, caused by the segregation of embrittlers, starts much earlier, if mechanical activation is taken into account. The rail wheels need turning every two years. The obtained results give a rough estimate of the safe operation period for the rail ways and wheels material endurance.

The size of link between crystallites can be purposefully changed and thus, it is possible to form monolayers of different elements on the grain boundaries. In this case, it is significantly important to know the elements' 
abilities to strengthen or weaken the grain boundaries in the particular material. However, in metallurgy it has been empirically established that $\mathrm{S}, \mathrm{P}, \mathrm{Bi}, \mathrm{Sb}, \mathrm{As}$ and some others are among the elements that cause steel embrittlement. However, some elements have properties that can both strengthen and embrittle materials (Kolesnikov et al., 2006). This factor depends on the grade steel. The problem of the material destruction process as a result of the segregation is complicated enough, since in polycrystalline metals the conditions of destruction occurrence depend on prevailing abilities of two processes. The first involves links' weakening between the grains due to different segregants' atoms, located on the grain boundaries, while the second is connected with the metals' plastic deformation.

The adsorptive film layers of alloying and impurity elements can be determined as a third body, or a lubricant between two interacting bodies (grains). This lubricant promotes both grains' sliding process, as well as material destruction. In polycrystalline materials crystal grains are displayed chaotically. Therefore, under external forces, applied to the material, there occurs a shear stress between the counteracting grains, which tries to shift the grains' initial position towards each other. However, the shifting can be suppressed by static and sliding friction forces. The grains' sliding process causes the immediate destruction of the material and reduces the polycrystalline material endurance properties. The above assumptions and conclusions can be defined as a so called "tribological durability hypotheses" (Bulgarevich et al., 2010).

This hypothesis was experimentally illustrated on the simplest model pattern, where the polycrystalline material was viewed as a set of cubic grains, making up a proper cubic lattice. The grain edge size was equal to $1 \mathrm{mkm}$, while the iron was taken as a material. It was especially important to determine the mechanism of the segregants' monoatomic (monomolecular) layers ability to tie the grains, as well as to find out any regularity in this process. The sliding friction coefficient between grains of the polycrystalline material (Kolesnikov et al., 2011) is:

$$
\mu=\frac{\Delta U}{P_{\max } \sigma_{e f}^{3}},
$$

where $\mu$ is the sliding friction coefficient, $\Delta U$ is the average potential barrier energy, surmounted at grains' sliding process, during the destruction processes of the polycrystalline material, $P_{\max }$ is the maximum compression power between grains, which is equal to the polycrystalline resiliency limit of low-carbon steel $\left[10^{8} \mathrm{~N} / \mathrm{m}^{2}\right.$ (Shahparonov, 1976; Kobushkin, 1970)], $\sigma_{\mathrm{ef}}$ is the average diameter of the grains interaction during the sliding process.

For an approximate estimation of $\Delta U$ value the energy of the segregant's monolayer formation on the grain boundary was taken, thus $\sigma_{e f}^{2}=10^{-12} \mathrm{M}^{2}$. This monolayer was treated as a crystalline phase. It was assumed that at the grains sliding process the structure of the adsorptive monolayer would be completely destroyed (Shahparonov, 1976; Kobushkin, 1970):

$$
\Delta U=\frac{\Delta H^{0}}{N_{A}} N,
$$

where $\Delta H^{0}$ is the mole energy at which the adsorptive layer's phase is formed, $N$ is the number of segregant's atoms on the grain surface. However, here the interaction between the segregants' layers and grains was not considered. The number of the segregant's atoms on the polycrystalline grain surface was determined by the structure of the segregants' layers, considering the values of the segregant's atoms covalent radii (Rabinovich \& Khavin, 1978):

Table 1. The number of segregant's atoms on the grain surface

\begin{tabular}{ccc}
\hline $\begin{array}{c}\text { Body-centered Cube lattice of the } \\
\text { segregant's layer }\end{array}$ & $\begin{array}{c}\text { Face-centered Cube lattice of the } \\
\text { segregant's layer }\end{array}$ & $\begin{array}{c}\text { Hexagonal Cube lattice of the } \\
\text { segregant's layer }\end{array}$ \\
\hline$\frac{\sigma_{e f}^{2}}{\left(2 R_{\mathrm{cov}}\right)^{2}}=N$ & $2 \frac{\sigma_{e f}^{2}}{\left(2 R_{\mathrm{cov}}\right)^{2}}=N$ & $\frac{4 \sigma_{e f}^{2}}{3 \sqrt{3}\left(2 R_{\mathrm{cov}}\right)^{2}}=N$ \\
\hline
\end{tabular}

where $R_{c o v}$ is the covalent radius of the segregant. 
According to the above data, the friction coefficients values for $\alpha$ - Fe segregant layer were derived. Afterwards, the discontinuous dependence of coefficient of sliding friction between grains and the segregant' element atomic number was determined.

It was noticed that $\mathrm{B}, \mathrm{C}, \mathrm{Al}, \mathrm{Co}, \mathrm{Ni}, \mathrm{Cu}, \mathrm{Rh}, \mathrm{Pd}, \mathrm{Ir}, \mathrm{Pt}$ have the maximum volume of coefficient of sliding friction, therefore, they have better strengthening properties as segregant elements.

A special interest was focused on $\mathrm{B}, \mathrm{C}, \mathrm{Co}$ and $\mathrm{Ni}$, the most available impurities, being alloying additions in steel. According to the experimental data, $\mathrm{S}$ and $\mathrm{P}$ were defined as the most harmful segregants.

The element's composition on the alloys surface of was analyzed and detected mode samples (Fe-matrix), containing such elements as $\mathrm{B}, \mathrm{Cu}, \mathrm{S}, \mathrm{P}$ with the help of the $\mathrm{x}$-ray photoelectron spectroscopy method.

The samples were pellets of 9-mm diameter and 1-mm thickness. The composition of the surfaces was studied by using an X-ray photoelectron spectrometer. The natural surface formed by heating in air was studied, and a pressure of $5 \times 10^{-6} \mathrm{~Pa}$ was therefore sufficient. The operation mode of an X-ray tube was as follows: the anode voltage was $U_{a}=9 \mathrm{kV}$ and the anode current was $\mathrm{I}_{\mathrm{a}}=49 \mathrm{~mA}$. X-ray photoelectron spectra were obtained for a constant transmission energy of an energy analyzer, which was a $180^{\circ}$ spherical deflector with the average-trajectory radius $\mathrm{r}_{0}=50 \mathrm{~mm}$. The absolute resolved energy interval with regard to the FWHM of the $\mathrm{AlK}_{\alpha}$ line was $1.2 \mathrm{eV}$. This value was chosen as a compromise one for which one could study both the fine structures of X-ray photoelectron spectra of core levels and the elements composition of the surfaces.

The above study is based on the analysis of the grains' possible sliding inside the polycrystalline material according to the assumed tribological durability hypothesis, which treats the segregant's layer between the interacting grains inside the polycrystalline material as a solid lubricant, promoting or preventing the sliding process between the polycrystals.

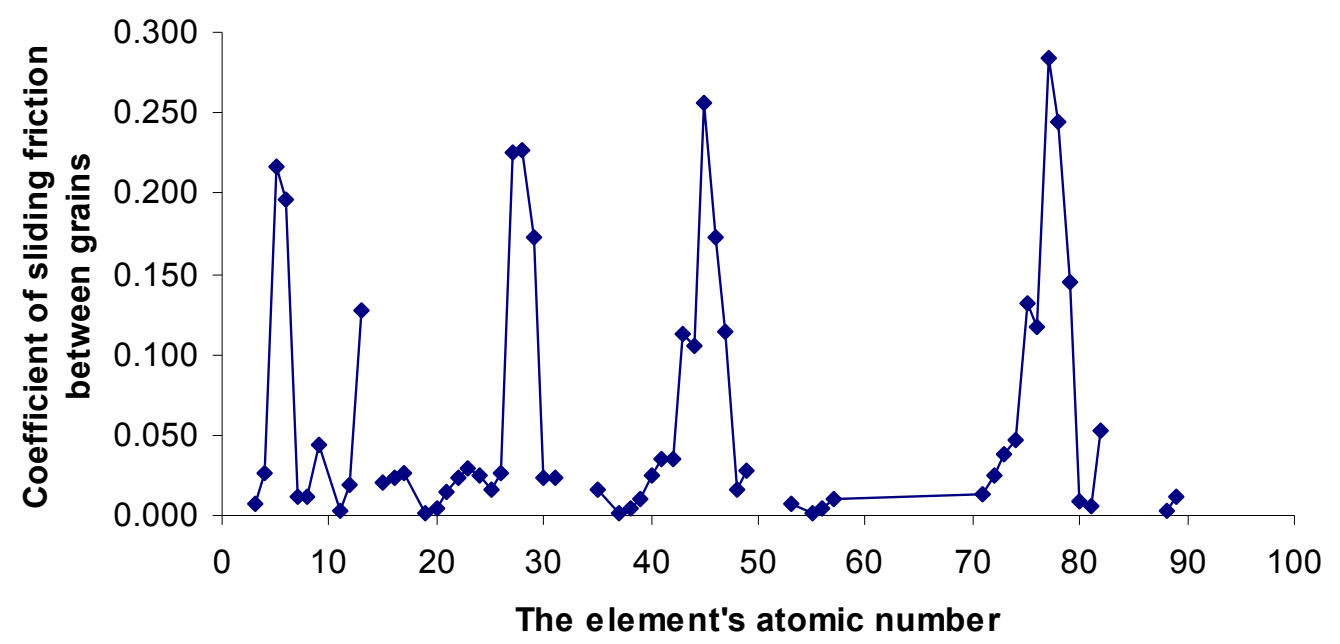

Figure 2. Dependence of the coefficients of sliding friction between $\alpha$-Fe crystallites on the segregant's atomic number in the periodic table, considering the presence of the monoatomic segregants layer between the grains 
Table 2. The calculations of the coefficients of sliding friction between $\alpha$-Fe crystallites, based on the segregant's atomic number in the periodic table, considering the presence of the monoatomic segregant layer between the grains

\begin{tabular}{cccccccccccc}
\hline Element & $\mathrm{Li}$ & $\mathrm{Be}$ & $\mathrm{B}$ & $\mathrm{C}$ & $\mathrm{N}$ & $\mathrm{O}$ & $\mathrm{F}$ & $\mathrm{Na}$ & $\mathrm{Mg}$ & $\mathrm{Al}$ & $\mathrm{P}$ \\
$\begin{array}{c}\text { Friction } \\
\text { coefficient }\end{array}$ & 0.028 & 0.103 & 0.216 & 0.196 & 0.011 & 0.011 & 0.043 & 0.013 & 0.019 & 0.127 & 0.082 \\
\hline $\begin{array}{c}\text { Element } \\
\text { Friction } \\
\text { coefficient }\end{array}$ & 0.024 & 0.026 & 0.007 & 0.019 & 0.060 & 0.091 & 0.117 & 0.100 & 0.066 & 0.104 & 0.226 \\
\hline $\begin{array}{c}\text { Element } \\
\text { Friction }\end{array}$ & $\mathrm{Ni}$ & $\mathrm{Cu}$ & $\mathrm{Zn}$ & $\mathrm{Ga}$ & $\mathrm{Br}$ & $\mathrm{Rb}$ & $\mathrm{Sr}$ & $\mathrm{Y}$ & $\mathrm{Zr}$ & $\mathrm{Nb}$ & $\mathrm{Mo}$ \\
Coefficient & 0.228 & 0.172 & 0.024 & 0.023 & 0.016 & 0.006 & 0.015 & 0.042 & 0.100 & 0.139 & 0.140 \\
\hline $\begin{array}{c}\text { Element } \\
\text { Friction }\end{array}$ & $\mathrm{Tc}$ & $\mathrm{Ru}$ & $\mathrm{Rh}$ & $\mathrm{Pd}$ & $\mathrm{Ag}$ & $\mathrm{Cd}$ & $\mathrm{In}$ & $\mathrm{I}$ & $\mathrm{Cs}$ & $\mathrm{Ba}$ & $\mathrm{La}$ \\
coefficient & 0.113 & 0.106 & 0.257 & 0.173 & 0.115 & 0.016 & 0.028 & 0.008 & 0.005 & 0.015 & 0.043 \\
\hline $\begin{array}{c}\text { Element } \\
\text { Friction }\end{array}$ & $\mathrm{Lu}$ & $\mathrm{Hf}$ & $\mathrm{Ta}$ & $\mathrm{W}$ & $\mathrm{Re}$ & $\mathrm{Os}$ & $\mathrm{Ir}$ & $\mathrm{Pt}$ & $\mathrm{Au}$ & $\mathrm{Hg}$ & $\mathrm{Tl}$ \\
coefficient & 0.055 & 0.102 & 0.150 & 0.189 & 0.132 & 0.117 & 0.284 & 0.244 & 0.146 & 0.009 & 0.026 \\
\hline $\begin{array}{c}\text { Element } \\
\text { Friction }\end{array}$ & $\mathrm{Pb}$ & $\mathrm{Ra}$ & $\mathrm{Ac}$ & & & & & & & & \\
coefficient & 0.052 & 0.012 & 0.046 & & & & & & & & \\
\hline
\end{tabular}

In most cases, the obtained estimations of our research coincide with those, which are presented in the work by Seah (1980), mainly, with the data in Figure 2. In the work (Briggs \& Seah, 1990) the energy volume, necessary for breaking the link between the grains was derived, the embrittlement-toughness diagram for the basic material (Fe matrix) and segregated elements was demonstrated. All the elements above the dotted line in Figure 1 (such as $\mathrm{C}$ and Mo), strengthen the links between the grains, and those, which are below the line ( $\mathrm{P}, \mathrm{Cu}$ and $\mathrm{S}$ ), weaken the link properties and cause Fe embrittlement. The effect degree depends on the distance between the point, which corresponds to the particular element, and a dotted line.

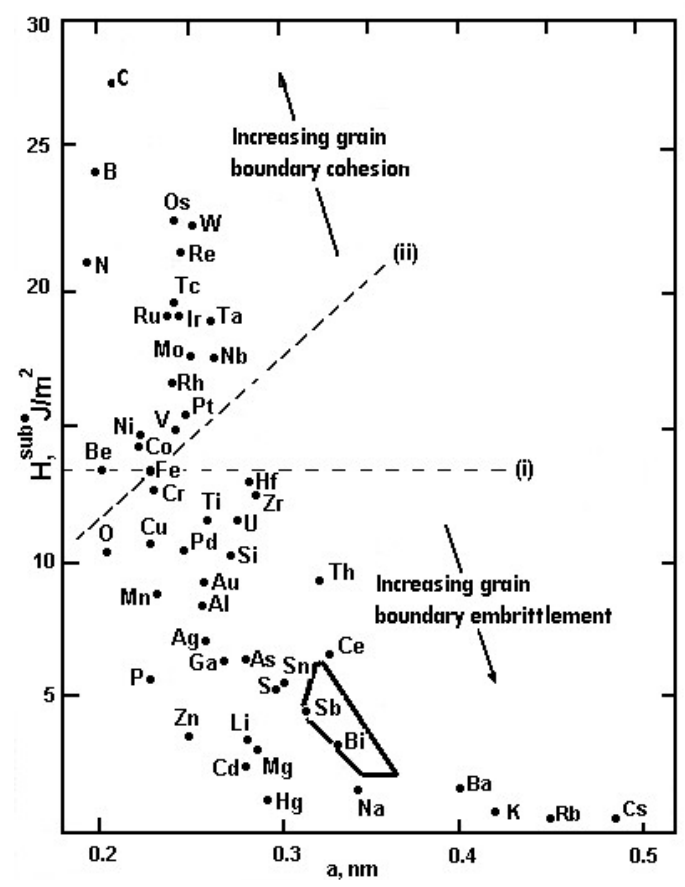

Figure 3. Adsorption-induced interface decohesion diagram (Briggs \& Seah, 1990) 


\section{Conclusions}

1). The segregation process of some chemical elements as $B, S$ and $P$ are found in the metal-polymeric "wheel-brake block" system by means of X-ray photoelectron spectroscopy methods.

2). The study shows that the segregants' diffusion from crystalline grains on the grain boundary surface is based on the dislocation mechanism.

3). The research considers and analyses the kinetics of the segregation process. The mechanisms of kinetics are experimentally confirmed.

4). The research reveals the periodical dependence of coefficients of sliding friction between Fe grain and the segregant-elements' atomic number on the grain surface.

\section{References}

Briggs, D., \& Seah, M. P. (1990). Practical Surface Analysis by Auger and X-ray Photoelectron Spectroscopy. Chichester: John Wiley \& Sons, Ltd.

Bulgarevich, S. B., Boiko, M. V., \& Akimova, E. E. (2006). Thermodynamics spontaneous chemical reactions induced by friction. Vestnik Rostov. Gos. Univ. Putei Soobshchen., 3, 107-112 (in Russian).

Bulgarevich, S. B., Boiko, M. V., Akimova, E. E., \& Korets, K. E. (2010). Tribological durability hypothesis of polycrystalline material and probable kinetic mechanisms of grain boundary segregation. Vestnik Rostov. Gos. Univ. Putei Soobshchen., 1, 20-29 (in Russian).

Heinecke, G. (1984). Tribochemistry. Berlin: Akademie.

Ermakova, N. U. (2006). Effect of interaction and fragmentation during grain formation deformation texture polycrystal. St. Petersburg (in Russian).

Kobushkin, V. K. (1970). Minimal Physics part 1. Leningrad: Leningr. Univ. (in Russian).

Kolesnikov, V. I., Kozakov, A. T., Sidashov, A. V., Kravchenko, V. N., \& Sychev, A. P. (2006a). A diffusive and segregative processes in contact -fatigue breakdown of a railway sprocket working surface in metal-polymeric conjugation. Friction \& Lubrication in machines and mechanisms, 8, 22-32 (in Russian).

Kolesnikov, V. I., Kozakov, A. T., Sidashov, A. V., Kravchenko, V. N., \& Sychev, A. P. (2006b). Diffusion and segregation processes in metal-polymer tribosystem. Friction and Wear, 27(4), 361-365 (in Russian).

Kolesnikov, V. I., Bulgarevich, S. B., Boiko, M. V., \& Feizova, V. A. (2011). Mechanoactivation in Friction and the Laws of Sliding and Rolling Friction. Journal of Friction and Wear, 32(6), 413-418 (in Russian).

Kozakov, A. T., Bulgarevich, S. B., Kolesnikov, V. I., Sidashov, A. V., \& Boiko, M. V. (2007, 24-28 September). Induced by friction and force loadings the damage of the wheel steals on the railway transportation. International Conference "Topical Problems of Continuum Mechanics", Tsakhkadzor, Armenia, 222-226 (in Russian).

Panchenkov, G. M., \& Lebedev, V. P. (1974). Khimicheskaya kinetika i kataliz (Chemical Kinetics and Catalysis). Moscow: Khimiya (in Russian).

Rabinovich, V. A., \& Khavin, Z. Ya. (1978). Kratkii khimicheskii spravochnik (Short Chemical Handbook). Leningrad: Khimiya (in Russian).

Seah, M. P. (1980). Adsorption-induced interface decohesion. Acta Metallurgica, 28, 955-962.

Shahparonov, M. I. (1976). Introduction to the modern theory of solutions. Moscow: Visshaya Skhola (in Russian).

Sorokin, V. G., Volosnikov, A. V., \& Vyatkin, S. A. (1989). Marochnik stalei i splavov (List of Steel and Alloy Grades). Moscow: Mashinostroenie (in Russian).

\section{Copyrights}

Copyright for this article is retained by the author(s), with first publication rights granted to the journal.

This is an open-access article distributed under the terms and conditions of the Creative Commons Attribution license (http://creativecommons.org/licenses/by/3.0/). 